\title{
As plantas que curam e as 'qualidades do ser': sobre ontologia e alteridade ameríndia
}

\author{
Plants that cure and 'qualities of being': on ontology \\ and Amerindian otherness
}

\author{
Marco Antonio Gonçalves \\ Programa de Pós-graduação em Sociologia e Antropologia/Instituto de Filosofia \\ e Ciências Sociais/UFRJ \\ Rua Monte Alegre, 336 - Santa Teresa \\ 20240-193 Rio de Janeiro - RJ - Brasil \\ marco@ifcs.ufrj.br
}

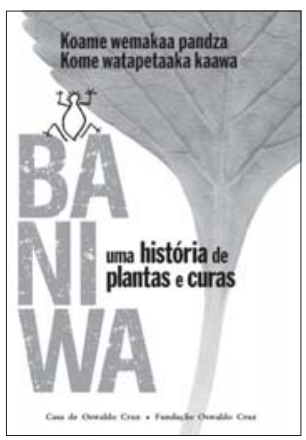

Koame wemakaa pandza kome watapetaaka kaawa - Baniwa, uma história de plantas e cura. DVCAM (72 min.). Direção de Stella Oswaldo Cruz Penido. Realização: Casa de Oswaldo Cruz/Fiocruz, Rio de Janeiro, 2005.
A ndré Fernando, personagem central desse filme sobre os Baniwa, põe em evidência uma possibilidade de ser e estar no mundo que desafia o nosso modo de pensar ocidental, em que tomamos como contraditórias as identidades baseadas em ontologias e percepções de mundos distintos. Portanto a questão que move o pensamento Baniwa - e por extensão o pensamento ameríndio - não se apóia no princípio do 'ser ou não ser', mas sim em um princípio no qual a diferença e a alteridade engendram uma complexidade que envolve soma e síntese, adição e não contradição. $\mathrm{O}$ ser, nesse universo, evocando aqui uma expressão da antropóloga inglesa Marilyn Strathern, é divíduo e não indivíduo, isto é, resultado de processos, de relações culturais e históricas.

André Fernando experimenta, na simultaneidade, o complexo de sua pessoa: presidente da Organização Indígena da Bacia do Içana (Oibi), vice-presidente da Federação das Organizações Indígenas do Rio Negro (Foirn), evangélico, liderança, intérprete de sua mitologia, sabedor do catolicismo, implementador das estratégias de reflexão sobre uma política de desenvolvimento sustentável para a região, empresário de visão quando fala da exportação do artesanato do rio Negro para a cadeia de lojas TokStok, vítima do veneno de seus inimigos que lhe querem mal, que invejam sua posição de liderança. Personagem fascinante porque conjuga os discursos político, social, cosmológico e mitológico para dar conta de suas relações com os demais índios e com os brancos. Stella Oswaldo Cruz Penido nos apresenta nesse bem-sucedido filme-etnografia esse personagem delicado e intenso, que condensa todos esses ingredientes, e a partir dele nos ajuda a refletir sobre o significado de ser e não ser índio hoje, na contemporaneidade.

A pesquisa que deu origem ao filme foi realizada com os Baniwa dos rios Içana e Aiari da região do rio Negro, entre 2002 e 2005. Os Baniwa são seis mil pessoas vivendo em 94 assentamentos na fronteira do Brasil com a Colômbia.

O filme inicia com o benzedor Felício Fontes narrando o mito de origem dos Baniwa, a origem das nações indígenas que habitam a região do rio Negro. Uma imagem da pedra de onde saíram todas as nações faz coincidir cinema e mito na busca da materialização da narrativa. Felício complementa dizendo que antigamente o benzedor era gente, agora é pedra. 
André Fernando narra duas versões sobre o surgimento dos brancos. Na primeira, os brancos surgiram da mesma maneira que os índios, da espuma branca formada pela cachoeira. Portanto esses brancos "são nossos parceiros hoje", os que procuram conversar, ajudar e defender os índios, pois tiveram sua origem na mesma água das corredeiras. A segunda versão enfatiza que os brancos surgiram de um episódio que envolveu traição, briga, morte e transformação. Uma cobra grande tinha como amante a mulher de um índio. O índio mata a cobra com uma flecha, da cobra surgem os vermes brancos e são estes que dão origem aos brancos. André Fernando conclui que esses são os "brancos que nunca vão gostar de nós", aqueles que invadem suas terras e que serão, eternamente, os inimigos: "a briga nunca vai acabar".

As duas narrativas sobre a origem dos brancos procuram dar conta do significado de ser branco hoje e das relações estabelecidas entre índios e brancos. Uma distinção importante que esclarece sobre as diferentes imagens dos brancos na contemporaneidade: aqueles que os índios conhecem pelo nome, com quem compartilham os mesmos interesses políticos e que são simplesmente seus amigos; e os outros que são considerados pertencentes a uma categoria de alteridade, a denotar inimizade e antagonismo. Portanto o mito produz uma versão para a origem dos brancos querendo, justamente, dar conta dessa nova relação com eles, que inclui a amizade, o companheirismo, a partilha de projetos comuns, e escapa assim de uma percepção abstrata da alteridade que os associava a Outros distantes.

Uma seqüência de planos apresenta o cotidiano de uma aldeia Baniwa: mulheres fazendo beiju, crianças carregando lenha, homens tocando flautas e dançando em uma casa. André Fernando apresenta a cena a partir de um discurso nativo-antropológico que procura descrever os Baniwa como uma sociedade composta por muitos clãs, enfatizando que entre eles existe forte hierarquia e que um deles é liderança da guerra e dos rituais. E continua a explicar tal fenômeno da hierarquia político-social dos clãs tendo o seu próprio caso como exemplo. Desde 1992 ele é uma das lideranças indígenas do rio Negro, fato importante na conquista da demarcação das terras e, também, no incentivo para que os índios trabalhassem em projetos de medicina alternativa tradicional.

A diretora pergunta: "Os mais velhos te vêem como liderança?" André Fernando diz que antigamente a criança nascia líder, bastava olhar para o seu cordão umbilical para saber se ela seria chefe da aldeia, e que hoje a questão da liderança é copiada dos brancos, a partir da noção política de eleição. Reconhece que os chefes eleitos manipulam um conhecimento que não é apenas de sua sociedade, mas do encontro e da relação com os brancos.

A professora Baniwa exemplifica a dualidade da tensa relação entre um interior e um exterior, a partir da qual se produz o ser Baniwa contemporâneo: as disciplinas ligadas aos brancos formam o núcleo comum (matemática, português, ciências, geografia), aquilo que expressa o modo da 'vivência' dos brancos, seus costumes e suas crenças; e as diferentes histórias dos velhos são consideradas como a 'biblioteca', os arquivos do povo Baniwa. Um plano de um menino a pesquisar 
plantas tradicionais, os remédios, ilustra a cena. Os alunos transformamse em pesquisadores de sua própria cultura, descobrindo novos significados pelo diálogo com os mais velhos, num incessante reaprendizado de sua cultura. Assim, meninos e meninas aprendem, na escola, como construir uma cultura Baniwa com base em percepções que, embora diferentes, não são necessariamente contraditórias: meninos vestidos com máscaras de papel apresentam cada um dos animais da floresta, como o tatu e a tartaruga, e logo em seguida manipulam computadores e rádios. A professora conclui dizendo: "Nossa cultura está sendo modificada, mas não vai acabar".

André Fernando assume o discurso político que se insere nessa nova modalidade de contato com os brancos, em que é porta-voz de uma nova condição social. Fala sentado em uma cadeira, tendo como pano de fundo não a natureza amazônica real, mas uma pintura, uma grande tela sobre uma pretensa 'natureza amazônica'. Produz, assim, um discurso político-estratégico-institucional que mostra para o branco que os índios estão organizados, social e politicamente, como produto direto da relação com os brancos e que o filme, ele mesmo, é mais uma das ritualizações dessas relações.

Nesse novo contexto das relações com os brancos surgem seqüências da arte Baniwa, a produção dos seus belos cestos para o mercado de consumo. Imagens de um grande depósito acentuam a produção dos cestos em escala industrial: eles são transportados por um carrinho e acomodados em prateleiras. A cena seguinte mostra um casal numa grande loja, comprando o cesto em importante centro urbano. André Fernando assume o discurso de um líder empresarial e afirma que o artesanato deve ser bem feito, ter bom acabamento (ser bem amarrado) e ter padrões de desenhos que representem a tradição Baniwa, pois desse modo pode-se colocá-lo no mercado de consumo.

Para ele, é de suma importância "acompanhar o mercado", "saber mudar para se adaptar", "se não morremos". Metaforicamente o cesto parece encarnar a mesma questão do ser Baniwa hoje, isto é, saber lidar com a 'tradição', ou melhor, repensar e atualizar a 'tradição' com base nas relações políticas, sociais e econômicas com os brancos.

Um homem de 75 anos relembra os tempos antigos, antes de os padres salesianos chegarem à região do rio Negro. Recorda da aldeia de outrora, e sua narrativa é coberta por imagens das décadas de 1930 e 1940, com trechos de filmes da Expedição de Fronteiras e fotos antigas da Missão Salesiana. O homem diz que não falava o português nem o nheengatu quando encontrou os padres, em 1940; somente baniwa e cubeo, esta última a língua de sua mãe. Narra as investidas dos padres para convencer sua mãe a deixá-lo estudar na Missão, para aprender "as coisas dos brancos". O padre dava uma razão prática para o aprendizado do português: em pouco tempo os brancos chegariam definitivamente à região e se os índios soubessem falar esse idioma não seriam enganados. Seu pai era contrário e perguntava ao padre quem cuidaria de seu filho se ele contraísse gripe ou sarampo. O padre respondeu que lá existia a Santa Casa - e o entrevistado acrescenta que naquele hospital tinha muito remédio: "Bons mesmo, não são como os remédios de hoje". Quando perguntado diretamente pelo padre se queria ir para a 
Missão, aceitou a proposta e recebeu "dez ternos de roupas". Seu discurso parece querer enfatizar uma escolha, ou seja, ele foi de livre e espontânea vontade para São Gabriel, para estudar e aprender as coisas do branco. Em seguida, aponta as contradições dessa relação com os padres: "O padre fez isso porque queria educar, civilizar, mas como em 1500 eles vieram é roubar a terra da gente".

Tratando desse universo contraditório, os planos seguintes destacam os índios ao redor de uma mesa com comida e bebida, rezando o pai-nosso. Agora André Fernando se apresenta ornado com um grande cocar e inicia discurso sobre o movimento indígena dizendo que "uma das pautas" era justamente a medicina tradicional. Acrescenta que ela está viva, mas que ninguém falou abertamente sobre a medicina tradicional até que a universidade se interessou pelo projeto. André explica para uma platéia Baniwa as atividades do projeto e conclui (a partir de uma pergunta feita pela diretora do filme) afirmando que as explicações vêm das histórias que contam para explicar um acontecimento, por isso não existe uma palavra específica para designar medicina tradicional. Acrescenta que o projeto causou um ótimo impacto para os Baniwa, pois hoje as pessoas discutem mais essas questões ligadas à medicina tradicional e as mulheres, os professores e os alunos estão pesquisando o tema. Cenas de plantas e modos de uso se sucedem.

Surge mais uma vez o marcador 'antigamente', a anunciar o discurso sobre a chegada dos brancos e os males do contato. Antigamente os Baniwa tinham o controle das doenças, não havia médico, não havia epidemia, não havia contato. Depois surgiram o sarampo e a catapora, que não eram doenças dos índios mas "doenças importadas para cá". Emerge então a questão de como incorporar os conhecimentos do benzedor e do pajé nesse programa de atenção à saúde indígena, que conta com médicos vindos do Rio Grande do Sul, enfermeiros do Paraná e dentistas de São Paulo. Como é possível deixar de incorporar o conhecedor tradicional, o pajé e o curador?

Surge um agente de saúde indígena enfatizando a seriedade de ser pajé: "[para] estudar pajé, [a pessoa] tem que ser comportada mesmo, tem que agüentar jejum de cinco anos, não pode comer assado, fazer sexo, não pode tomar bebida quente e não pode brincar com outras pessoas". Conta que se convenceu da verdade curativa do pajé ao assistir uma sessão de cura: pode-se limpar bem o local da sessão, mas quando o pajé cura, aparece uma pedra ou um pedaço de pau que ele mostra como causa da doença. Foi assim que ele passou a acreditar, mas ressalva que "não é todo pajé que sabe curar e tem pajé que sabe enganar, quer ganhar e não curar".

Entra em cena André Fernando encarnando o personagem de paciente de um pajé. Este entra na mata e tira uma raiz, que dá para André Fernando usar com remédio contra mánhene. André Fernando explica que o diagnóstico surge do conhecimento mitológico, das histórias. Se o pajé diagnostica o mal como mánhene, sabe qual é a planta que cura. Mánhene é a "última doença do mundo", foi criada por Kowai, o demiurgo Baniwa. Kowai retirou um pouco de cabelo de sua axila e o transformou em veneno para este mundo. E assim como criou a doença, criou também seu remédio da cinza do seu cigarro. 
André Fernando conta sua experiência com a doença, quando baixava de canoa para a cidade acompanhando seu tio. Este o curou dandolhe uma planta que trazia na canoa: "Era mánhene, não era outra coisa". Já foi acometido quatro vezes pelo mal. Conta que quando viajava de barco grande teve um sonho no qual estava vivo, mas seu corpo encontrava-se num túmulo. Quando o barco parou numa cidade da Colômbia, ele foi a uma feira próxima ao porto, procurar algo para comer, e lá encontrou um pajé (não sabe identificar de que etnia) que, ao vê-lo, sabia tudo sobre sua vida e disse-lhe que estava doente: os inimigos de André Fernando sabiam que ele estava por lá e não queriam que ele retornasse. O pajé leu sua mão e pediu que ele fizesse um trabalho para se livrar da doença e curar-se. Surge assim a idéia do veneno associada à inveja, à inimizade, à disputa política num mundo no qual as qualidades das relações implicam diretamente o bem-estar ou o mal-estar físico-psíquico das pessoas.

O senhor de 75 anos aparece dizendo que o que impede que a Oibi vá "para frente" são duas coisas: a inveja e o veneno. Acentua, assim, a lógica indígena da percepção das relações sociais e suas relações com os poderes patogênicos, que dão conta da complexidade do ser e estar no mundo Baniwa.

André Fernando discursa, como vice-presidente da Foirn, sobre o Programa Regional de Desenvolvimento Sustentável da Região do Rio Negro, e conclui que o movimento indígena trouxe uma 'liberdade' que implica diretamente uma não-discriminação: "Nós sofremos muita discriminação, mas o movimento abre para a liberdade". Na cidade, mostra sua casa de três quartos, bem equipada e mobiliada. Conta que durante quatro anos morou na casa do pai porque não tinha tempo para fazer sua própria casa. Diz que procura sempre explicar para os seus filhos o que significa o seu trabalho: "Estamos aqui na cidade por um tempo, essa coisa de liderança pode mudar e, por isso, nós comemos como Baniwa e falamos Baniwa. No caso de voltarmos para a aldeia, as crianças não sofrerão um choque alimentar e cultural". Continua refletindo sobre as possíveis contradições entre seu discurso e sua prática: "Se eu luto por uma escola diferenciada lá na aldeia, isso é uma contradição, porque nós estamos aqui na cidade... um risco para a liderança de falar e não praticar... filho de uma liderança... não sabe falar Baniwa... isso seria muito ruim".

Sua esposa diz que não se acostuma com a cidade, tem medo que os carros atropelem seus filhos, que alguém faça mal a eles. Vai até o quintal da casa e mostra remédios para dor de barriga. Pega outra planta e diz que é contra a inveja. Dá para o seu marido usar dentro de uma bolsa quando vai às assembléias indígenas e quando viaja, "porque muitas pessoas querem mal a ele". Acrescenta que, por esse motivo, André Fernando está sempre doente: "As pessoas pensam que ele está ganhando muito dinheiro e, com inveja, fazem mal. Ele tem dor de cabeça, o coração bate muito forte, fraqueza...".

André Fernando diz ser previsível que qualquer pessoa, nesse trabalho de liderança, passe por sofrimentos, seja perseguido ou atacado. Para os Baniwa, "as pessoas só entram na coisa se tem um pagamento, mas encarar o desafio de construir as coisas, não encaram não". Portanto 
para esse líder o sofrimento faz parte de sua construção política, seja na relação com o mundo dos brancos, ou na relação com o mundo indígena.

A professora afirma que, antigamente, apenas os velhos sabiam fazer o mal, mas o faziam somente quando se tratava de algo muito grave. Hoje em dia, acrescenta, "qualquer um por qualquer coisa está botando veneno, soprando... a gente tem que ter sempre cuidado, não é como antigamente...".

Um plano nos leva até uma igreja evangélica e ficamos sabendo que atualmente $80 \%$ dos Baniwa são evangélicos. Explica-se que a doutrina começou a ser pregada por uma americana chamada Sophia Miller, que evangelizou primeiro os vizinhos Curripaco. E assim como o discurso sobre o pajé exige provas de sua veracidade, a evangélica também foi testada. Duvidando de seu poder, os índios envenenaram sua comida mas ela sobreviveu, dando provas, então, de que era poderosa. Como conseqüência, o evangelismo imperou entre os Baniwa. O próprio André Fernando se assume como evangélico. A diretora do filme pergunta se há conflitos entre as práticas dos evangélicos, os católicos e a cultura tradicional Baniwa. André Fernando vê a diferença cultural não como contradição mas como adição - "a partir do catolicismo, do evangelismo e da tradição Baniwa pode surgir uma coisa diferente" - e reconhece que todos erraram quando não procuraram compreender a tradição Baniwa e integrá-la no projeto evangélico ou católico.

O que se percebe no discurso de André Fernando, o que nos leva a refletir sobre a nova configuração das relações entre índios e brancos no Brasil, é que há uma agência no processo de construção dessa relação com o outro: o evangelismo agora é deles, não é simplesmente algo de fora; a busca da tradição, das plantas que curam não é apenas de um projeto universitário, mas é parte dos interesses dos Baniwa, que incorporam e refletem essas relações a partir de um simbolismo complexo que leva em conta inúmeros fatores: história das relações interétnicas, cosmologia Baniwa, relações sociopolíticas com o interior e o exterior da sociedade.

Os planos finais do filme demonstram a complexidade do ser Baniwa hoje, a possibilidade de pensar em conjunto, as diferentes ontologias que dão significado ao mundo e que constroem de forma tensa, porém harmoniosa, a pessoa Baniwa: evangelismo, pajés, venenos, política, cidade e floresta. O pajé conta que sonhou com André Fernando e que, em seu sonho, o líder estava no meio de um rio nadando quando um peixe o pegou. Confirma que sua doença é "um veneno para matar mesmo, mánhene". Conclui que se existe o veneno, existe também sua cura, justificando assim seu trabalho: "Alguma pessoa cura, nem todo mundo cura... só na pajelança. A gente entra na boca dele e pega lá, ele lá dentro, o mánhene". Descreve o uso do paricá, que é crucial para ver onde está a doença. Cheira-o quatro vezes e na última vê tudo: onde começa, o que deram para ele, o que está matando seu paciente, o que o está envenenando. O pajé diz que vai ajudá-lo com rezas. André Fernando descreve seus sintomas: tem dor de cabeça e o coração treme. Conclui que a doença desaparece com o tratamento, mas o inimigo, jamais. O pajé sopra André Fernando com a fumaça do tabaco e benze-o com rezas. Termina dizendo: "É somente isso, a doença é forte, mas não vai acontecer nada". 